\title{
Agronomic and economic efficiency of chemical reclamation of Solonets land areas
}

\author{
Irina Trotsenko ${ }^{1, *}$ and Yuliya Korchevskaya ${ }^{1}$ \\ ${ }^{1}$ Omsk State Agrarian University named after P.A. Stolypin, 1, Instituskaya Square, 644008, Omsk, \\ Russia
}

\begin{abstract}
Long-cultivated solonets and saline land areas have become a significant reserve of agricultural production increase. The efficiency of reclamation methods or technologies is determined according to their reclamation and agronomic effect. In the present study we investigate the influence of single and repeated land gypsuming of multinatrium solonets of sodium salinization upon crop yield. The economic effect of this method is also analyzed. The study was carried out in Western Siberia for a long period of time (over 20 years). We used phosphogypsym (bypass product of phosphor fertilizers) as an ameliorator. The quantity of gypsuming for reclamation was calculated according to soil layer sizes $-5,10$, and $20 \mathrm{sm}$. The results suggest that chemical reclamation of multinatrium solonets areas is cost-effective in case of repeated gypsuming. It's essential to conduct random reclamation procedures in solonets land areas to increase sustainable and heavy yield. Reclamation efficiency is evaluated according to soil quality development and economic inputs on reclamation.
\end{abstract}

\section{Introduction}

Long-standing experiments in the system of nonmoldboard technology of solonets cultivation without chemical reclamation resulted in the absence of soil reclamation of the areas. A.S.Migutsky and R.D.Zubareva $[1,2]$ laid the experiment on the land areas with the level of ground water between 3,5-4,5 $\mathrm{m}$. Our research was carried out on the crusted solonets areas of sodium salinization with ground water level from 1,5 to $3,5 \mathrm{~m}$. Both studies showed the failure of grain crops yield on the examined territories. According to N.V.Semendyayeva (2005) the efficiency of gypsum introduction is higher in multinatrium solonets land areas in the north of the forest-steppe zone of the Barabinsk plain than in the areas with little or medium content of sodium. Gypsum implementation increases grain crops yield up to $11-32 \%$ on the land areas with little sodium content, and to $35-56 \%$ on the territory with medium content of sodium. As for multinatrium solonets land areas its cropping capacity increases in 3 - 10 times depending on the gypsum quantity and in comparing to unreclaimed solonets land areas (control) [3, 4].

Considering the results of experiments in different regions of Western Siberia we suggest that productivity of unreclaimed solonets land areas achieves the quality of soils of medium fertility regardless of the solonets land type after gypsuming. Grain crop yield

*Corresponding author: ia.trotsenko@omgau.org 
on the reclaimed areas is about $60-80 \%$ comparing to chernozem or meadow-chernozem soils in the nearby territory [5].

Phenological observations have shown that in case of gypsuming crop plants growth stage comes 10-15 days earlier. These favourable conditions are very important in the periods of long cold spring and early summer-autumn ground frosts. Gypsuming influences greatly on plant density and botanic content of sward, this is resulted in hay general nutrient density $[6,7]$.

\section{Research Objective}

Long-standing experiment in acidification and gypsuming of solonets soil was carried out in the territory of the Omsk Region in Western Siberia. The results show that the soil should be re-reclaimed on the $6^{\text {th }}-7^{\text {th }}$ year after acidification. In case of solonets gypsuming the aftereffect reclamation characteristics went down by half on the $15^{\text {th }}$ year of reclamation. In 15 years repeated reclamation of the across solonets soil site (control) and the once gypsuming soil site ("background") samples was tested by three doses: the control sample included 8 tons per hectare for reclamation of gypsum within $0-5 \mathrm{~cm}, 16$ tons per hectare for reclamation of gypsum within $0-10 \mathrm{~cm}$, and 32 tons per hectare for reclamation of gypsum within 0-20 cm [8].

\section{Results}

The results of crop yield are presented in Table 1. They include the data of the experiment of phospogypsum $(\mathrm{PhG})$ implementation in the period of more than 35 years.

The crop yield changes in dependence of precipitation and their distribution during the vegetation period. Also it depends on reclamation stage and the year of plant formation.

According to the data two years from the first three after re-reclamation were arid only 112 and $67 \mathrm{~mm}$ of rainfall fell respectively during the vegetation period. Conversely, the following year was extremely humid - $379 \mathrm{~mm}$ of rainfall fell during the growing period. The soil included salt in the soil in the proportions of $146-204$ tons per hectare in single gypsuming; 151 - 182 tons per hectare in repeated gypsuming; control site contained 78 - 111 tons per hectare, and "background" solonets site included $114-133$ tons per hectare. Despite extreme conditions and high degree of soil salinization the introduction of rotation of salt-resistant crops - barley - millet - barley influenced on crop yield on the plots with single gypsuming with doses of 16 and 32 tons per hectare and the plots with repeated gypsuming with doses of $0,83-1,20$ tones of fodder units per hectare. The "absolute" soil site couldn't be sown, the "background" soil plot yielded 0,24; 0,0 and 0,58 tons of fodder units per hectare.

Table 1. Data of crop yield in the period of 20 years, tons of fodder units per hectare.

\begin{tabular}{|c|c|c|c|c|c|c|c|c|c|}
\hline \multirow{3}{*}{ Type of usage } & \multicolumn{4}{|c|}{ Single gypsuming } & \multicolumn{4}{|c|}{ Repeated gypsuming } & \multirow{3}{*}{$\begin{array}{l}\text { LSD }_{0.05} \\
\text { (LSD - } \\
\text { least } \\
\text { significant } \\
\text { difference) }\end{array}$} \\
\hline & \multirow[b]{2}{*}{ Control } & \multicolumn{7}{|c|}{ Dose of PhG. tons per hectare } & \\
\hline & & 8 & 16 & 32 & Background & 8 & 16 & 32 & \\
\hline $\begin{array}{c}\text { Grain crops } \\
\text { (the first } 10 \\
\text { years of PhG } \\
\text { aftereffect) }\end{array}$ & 0 & 0.44 & 0.71 & 0.81 & 0.30 & 0.79 & 0.98 & 1.04 & 2.20 \\
\hline $\begin{array}{l}\text { Sweet clover } \\
\text { (the first } 10 \\
\text { years of PhG }\end{array}$ & 0 & 1.08 & 1.51 & 2.53 & 0 & 1.80 & 3.00 & 3.68 & 1.03 \\
\hline
\end{tabular}




\begin{tabular}{|c|c|c|c|c|c|c|c|c|c|}
\hline aftereffect) & & & & & & & & & \\
\hline $\begin{array}{c}\text { Perennials } \\
\text { the second 10 } \\
\text { years of PhG } \\
\text { aftereffect) }\end{array}$ & 0.013 & 0.96 & 1.37 & 1.83 & 0.16 & 1.91 & 1.94 & 2.10 & 0.48 \\
\hline $\begin{array}{c}\text { Natural } \\
\text { transform in } \\
\text { the medow } \\
\text { the second 10 } \\
\text { years of PhG } \\
\text { aftereffect) }\end{array}$ & 0 & 0.43 & 0.46 & 0.93 & 0 & 0.95 & 0.94 & 0.97 & 0.15 \\
\hline Annual yield & - & 0.72 & 1.01 & 1.52 & 0.11 & 1.36 & 1.72 & 1.95 & \\
\hline $\begin{array}{c}\text { Average } \\
\text { gypsum gain } \\
\text { per ton }\end{array}$ & - & 0.09 & 0.07 & 0.05 & - & 0.17 & 0.09 & 0.05 & \\
\hline
\end{tabular}

During the after reclamation period they made an attempt to introduce zone lying fallow and grain rotation of wheat - wheat - barley - oat. But the results showed the failure of the experiment. Despite the fact that the wheat was the first after fallow crop in the cycle and the decrease of salinization made 120 - 170 tons per hectare the crop yield reduced twice in comparison with foregoing crops. It became the result of high aridity in the area. The next year seedlings died in the same conditions.

To encourage successful development of reclamation sweet clover under switchgrass cover was sown. Some researchers agree that sweet clover, cultivated on solonets land areas, is an efficient phytoreclamation crop. According to A.S.Migutsky and G.I.Makarova pure sweet clover cultivation with the usage of perennials can become a potential crop for reclamation of solonets land areas in the steppe and forest-steppe zones (Migutsky A.S.). At the end of the $19^{\text {th }}$ century, analyzing the experience of Californian landlords, Gilgard wrote that sweet clover, especially its white type, was a strong sun and salt resistant crop. Similar conclusions were drawn by L.N.Luzin on the results of special research in the Northern Kazakhstan and by V.I.Kirushin, Academician of the Russian Academy of Agricultural Sciences (RAAS). Sweet clover well-developed root system reaches the depth of 0,5 $\mathrm{m}$, penetrating nonfilterable solonets horizons and ploughing them. The withdrawal of ready soluable salt from the upper horizons and bypass products of chemical reclamation is conducted through the drains, made by dead and decomposed plant roots (Ubogov et al.).

During our research sweet clover sowing increased the productivity of crusted solonets soil significantly. On the reclaimed sites the output of the herbage made 1,7 and 3,1 tons of fodder units per hectare in accordance to the aftereffect gypsuming in the quantity of 16 and 32 tons per hectare at single chemical reclamation and the quantity from 3,9 to 4,7 tons of fodder units per hectare at its repeated introduction. High quality hay from the second year yield of sweet clover was obtained in the quantity of 1,$9 ; 1,9$ and 2,0;2,6 tons of fodder units per hectare respectively.

According to the results it became obviously impossible to use crusted solonets in field rotation even with a full cycle of gypsuming. As such the studied land plots were transformed in the meadow with multicomponent mixture of sweet clover, alfalfa, awned wheat grass, bromegrass and Psathyrostachys juncea.

There are controversial opinions about the influence of perennials on the salt content in solonets soil. Plants develop deep root system and carry out Ca salts as well as significant quantity of Na. After dying and mineralization of plant deads carbon dioxide is released in big amounts. There is also a transformation of calcium carbonate into bicarbonates, which displace sodium from absorbing complex. These processes enable sodium formation in soils (Eremchenko, 1997). The results are dependent on the conditions of plant development and the content of soil solution on the land areas where the plants are grown. 
The perennials yield was at the acceptable level (no lower) than in reclamation period $(0,63-1,10$ tons of fodder units per hectare) despite the fact that on the tenth year after repeated reclamation plant density formation survived in difficult conditions of moisture and strong salinization up to $230-250$ tons per hectare (control $128-163$ tons per hectare). The most productivity of plant density was shown in the following five years after meadow formation: the average amount of 16 tons per hectare for the soil layer of $0-20$ $\mathrm{cm}$ and 32 tons per hectare for the soil layer of $0-30 \mathrm{~cm}$. In case of single gypsuming it encouraged 1,6 and 2,2 tons of fodder units per hectare, and in case of repeated gypsuming $-2,4$ and 2,5 tons of fodder units per hectare respectively. In the following years (the fifteenth year after reclamation) the crop yield decreased and made $0,4-0,9$ tons of fodder units per hectare despite of alfalfa and sweet clover deficit and bromegrass and Psathyrostachys juncea excess in the plant density formation (Table 1).

These results suggest that the change of main characteristics of solonets soils after a 10 year reclamation period of grain crops cultivation and perennials growing increased significantly the productivity of the crusted multinatrium solonets soils in spite of weather conditions instability, influencing upon the level of soil salinization and dynamics of other characteristics of soil fertility. In this way the first years of perennials growing posed the question about the recommendations for the short-term effect of gypsuming as a reclamation method in unirrigated conditions with an average annual precipitation of less than $350 \mathrm{~mm} \mathrm{[7,8].}$

In every studied year the crop yield exceeded the LSD value significantly on the reclaimed areas. The results corresponded to the data of A.S. Migutsky's research in the Om'- Irtyshsky interfluves. There was observed the same content of exchange sodium in solonets soils; at the control plot there was no yield in all years. Only sweet clover once provided refund for the costs of sowing seeds. Less than 0,1 ton of production was obtained on non-reclaimed plots, while in the areas with a dose of gypsum of 32 ton per hectare there was shown a result of more than 3 tons of fodder units per hectare. On average, every year the yield was $0,7-1,7$ tons of fodder units per hectare.

During 20 years of observation (after repeated reclamation), including the period of meadow formation, the most stable and high yields were obtained in solonets soils with gypsum introduction for metathetical calcium deficit in tilth-top soil of $0-20 \mathrm{~cm}$ reclaimed once with the dose of 32 tons per hectare. The total yield made 23, 9 tons of fodder units per hectare with an average annual yield of 1,5 tons of fodder units per hectare. Reducing the gypsum dose resulted in a significant reduction in yield.

Repeated reclamation provided with maximum production output in all plots from 23,6 to 29,1 tons of fodder units per hectare. Beside the weather conditions the usage type influences upon the crop yield. The cultivation of wheat for grain is inefficient in the conditions of fluctuating salt regime. The wheat and straw yield together made only $0,3-$ 9,6 tons of fodder units per hectare. These data correspond to the research of O.Z. Eremchenko in the Southern Transurals. They observed the yield increase to $0,1-0,2$ tons per hectare on the gypsum plot of middle solonets soil. According to V.S. Kursakova nonperennial crops (oat, wheat) cultivation in the conditions of hydrogenic moisture regime leads to soil salinization in a similar way as in the soils without cultivation. In her opinion, the plants were severely affected by salinization and the wheat yield was low, because of oversaturation of soil solutions with products of exchange and their weak outflow in the first years of reclamation $[8,9]$.

In conducting of economic analysis of reclamation costs many researchers estimate the gypsum efficiency by the value of the increase per 1 ton of ameliorator. So in general the highest increase per 1 ton of gypsum provides a dose of 8 ton per hectare, which is added repeatedly in the quantity of 0,2 tons of fodder units per hectare. The total yield becomes 
higher after introduction of a full dose of ameliorator, calculated for reclamation of the whole root layer $0-30 \mathrm{~cm}$ (Fig.1).

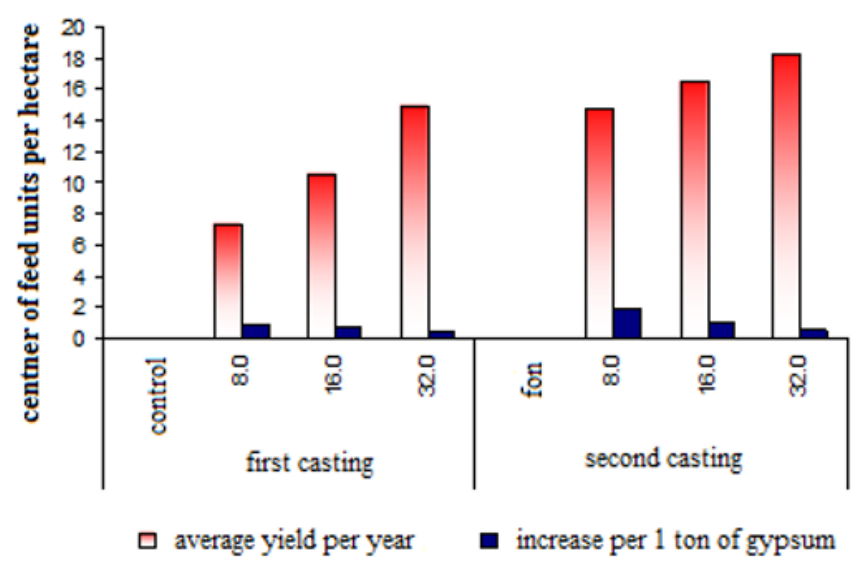

Fig. 1. Influence of ameliorator dose upon crusted multinatrium solonets productivity.

To encourage the consolidation of the reclamation effect a number of measures should be arranged in the reclaimed areas. In recent years there has been a significant decline in the yield quantity. It has become the result of the absence of periodic tillage and the need to meadow reformation not the repeated salinization.

As such, repeated reclamation has the advantage of increasing the productivity of the solonets soils. In repeated gypsuming subsurface calcium is involved in exchange processes. So it is possible to decrease calculated dose by half or calculate it for a layer of 0 - $10 \mathrm{~cm}$ within perennial meadow transformation on the solonets soils with sodium salinization.

Economic efficiency of solonets soils reclamation in Western Siberia is the basic criteria of their evaluation in the conditions of market economy. The data of the analyses of crusted solonets soils reclamation prove their insufficient effectiveness [10, 11, 12]. Reclamation technology needs large additional costs and requires long period of payback, which is equal to the aftereffect period of deep tillage. This period is also characterized by low yield increase (Fig.2).

Using our data we examine cost-effectiveness of repeated gypsuming. In order to calculate the economic efficiency of crusted solonets soils gypsuming in single and repeated reclamation we consider crop yield data in different options - absolute control with gypsum introduction in a dose of 32 tons per hectare - "background" (added once) and gypsum introduction in doses of 8,16 and 32 tons per hectare (added repeatedly after 15 years).

In the absolute control option of the multinatrium solonets soils there was practically no crop over 20 years of experience, despite soil treatment and crop sowing. When carrying out reclamation of such soils, the question arises of choosing the optimal dose of gypsum to produce stable crops.

In the case of single reclamation with the use of high calculated dose of gypsum - 32 tons per hectare by the content of exchange sodium - the highest total output of 23,9 tons per hectare and maximum net income of 12,3 thousand rubles were obtained. According to the options with 16 and 8 tons per hectare of gypsum net income was lower. It amounted to 7,9 and 4,2 thousand rubles respectively. At the same time with the dose increase the cost of 1 ton of fodder units per hectare decreases as the overall output increases. Additional reclamation costs are compensated in the period of three - four years. 
The data received from the "background" option show that the reclamation effect begins to decrease in 15 years. Since the cultivation costs are several times higher than the obtained amount from the sale of the product, it is necessary to repeat gypsuming.

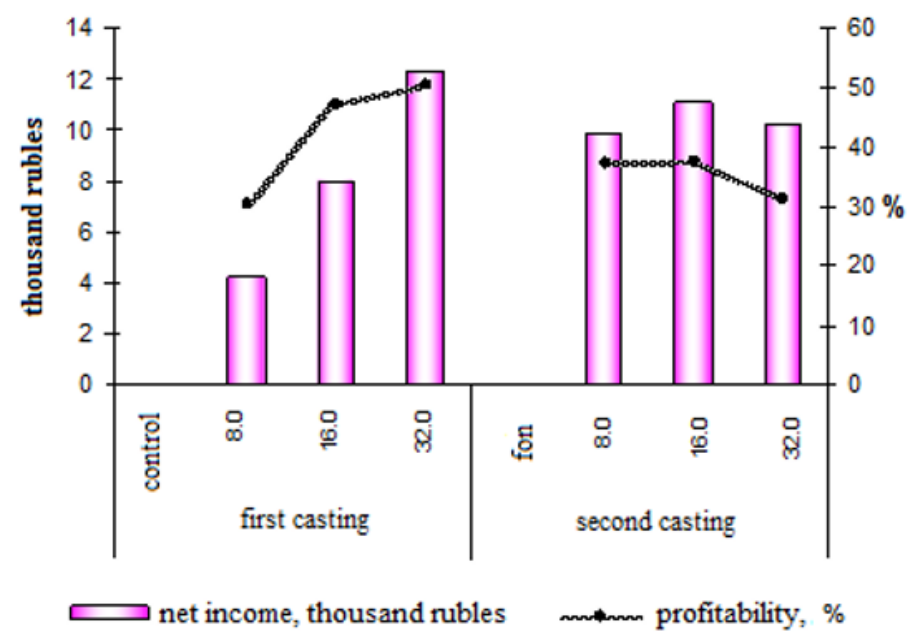

Fig. 2. Economic efficiency of gypsuming of crusted solonets of sodium salinization.

In repeated gypsuming in spite of extra costs for reclamation the product cost price is about 1 thousand rubles. According to the option with a dose of 32 tons per hectare, net income of 10,2 thousand rubles was received. It is not much lower than the obtained income from the option of 16 tons per hectare which made 11,1 thousand rubles. The profitability of repeated gypsuming makes $37 \%$ in case of dose introduction of 8 tons per hectare, calculated for a layer of $0-10 \mathrm{~cm}$ and 16 tons per hectare, calculated for reclamation of a layer of $0-20 \mathrm{~cm}$. The profitability of repeated gypsuming makes $31 \%$ using a dose of gypsum calculated for a layer of $0-30 \mathrm{~cm}$. So the costs are compensated on the third to fourth year of reclamation.

\section{Conclusion}

The productivity of soil areas with high specific weight of solonets in the absence of reclamation is very low due to the presence of solonets spots. Therefore, it is necessary to carry out selective contour reclamation measures in order to obtain high and stable crops on the complex land areas with sodium soils. The efficiency of reclamation is assessed by changing the properties of the soil and by the economic efficiency of reclamation costs.

The results of the research suggest that repeated gypsuming on the multinatrium solonets soils is economically advantageous.

The introduction of gypsum-containing ameliorators should be combined with the mandatory deep soil tillage. The obtained profit was 4-5 times less than in the options with deep tillage when gypsuming by fine treatment with partial preservation of the salt horizon. These results are conclusively proved by many years of reclamation experiments in Hungary and in Western Siberia by L.N. Skipin and others [13, 14, 15. 16].

\section{References}

1. V.V. Kunintsev et al., The Basis of Land Use System of New Generation in the Stavropol Region (Stavropol State Agrarian University, Stavropol, 2013) 
2. L.G. Bogatyrev, M.N. Maslov, A.I. Benediktova, M.I. Makarov, The Assessment of Soils and Lands (basic indicators and criteria), monograph (MAX Press, Moscow, 2017)

3. Wenjun Xie, Qingfeng Chen, Lanfang Wu, Hongjun Yang, Yanpeng Zhang, Soil and Tillage Research 198 (2020)

4. A.N. Kostyakov, The Basis of Reclamation (Media, Moscow, 2011)

5. L.M. Dokuchayeva, R.E. Yurkova, The Ways of Efficiency Increase of Irrigated Agriculture 50, 68-73 (2013)

6. E.P. Denisov, A.P. Solodovnikov, K.E. Denisov, I.S. Poletaev, V.V. Zuev, Scientific Life 2, 35-41 (2018)

7. L.O. Karpachevsky, Soil Science 2, 249-250 (2010)

8. L.V. Berezin, A.M. Gindemit, Proceedings of Russian Academy of Agricultural Sciences 4, 31-34 (2013)

9. Z.I. Voropaeva, I.A. Trotsenko, A.I. Parfenov, Eurasian Soil Science 44(3), 314-325 (2011)

10. L.V. Berezin, A.M. Gindemit, I.A. Trotsenko, Bulletin of International Institute of Nutrition 4, 9-16 (2017)

11. L.V. Berezin, A.M. Gindemit, O.F. Khamova, E.V. Paderina, Eurasian Soil Science 47(11), 1138-1143 (2014)

12. L.V. Berezin, Bulletin of Omsk State Agrarian University 2(14), 22-27 (2014)

13. L.V. Berezin, Biogeosystem Technique 2(2), 133-149 (2014)

14. G.T. Balakay, L.M.Dokuchaeva, R.E. Yurkova, O.Yu. Shalashova, Scientific Journal of the Russian Research Institute of Reclamation Problems 4(20), 39-56 (2015)

15. L.N. Skipin, Modern scientific and practical solutions in agricultural complex: Proceedings of All-Russian scientific and practical conference, 551-557 (2017)

16. L.N. Skipin, O.V. Udartseva, V.S. Petuhova, E.V. Zhilyakov, IOP Conference Series: Earth and Environmental Science, International Conference on Sustainable Cities 177, 012038 (2018) 